\title{
ESTIMATION OF CARBON STORAGE IN SHRUBS IN CEMPAKA SUBDISTRICT, BANJARBARU
}

\author{
${ }^{1}$ Dienny Redha Rahmani, ${ }^{2}$ Wahyunah, ${ }^{1}$ Virgina Maria Louisa \\ ${ }^{1}$ Graduate Program of Natural Resources and Environmental Management \\ email: dn.redha@gmail.com \\ 2Department of Biology, Faculty of Mathematics and Natural Sciences \\ Lambung Mangkurat University, Banjarbaru, South Kalimantan
}

\begin{abstract}
The amount of critical lands, mostly wetlands, in South Kalimantan Province has increased, and it requires quick and sustainable recovery. An analysis of the potential of shrubs in vegetation indicated that shrubs had an important role in greening a city either in mixed vegetation or in vegetation filled with shrub strata. This basic characteristic becomes the basis of the study on carbon storage in shrubs and their potential as the alternative vegetation in the recovery of degraded lands. The study was conducted in Cempaka Subdistrict, Banjarbaru. Samples were taken at three stations, each of which consisted of three plots sample plots measuring $4 \times 4 \mathrm{~m}$. Carbon storage in the shrubs was estimated using the main stem diameter, and converted into table of average carbon estimation. The shrub canopy was estimated based on the types of canopy using formulas and types of canopy volume. The results showed that the average value of carbon storage contained in the shrubs per plot was $15.54 \mathrm{lbs} / \mathrm{m}^{2} /$ day, with an average canopy volume per plot was $0.40 \mathrm{~m}^{3}$. In 1 ha of growing area, shrubs was estimated to absorb carbon up to $155,416.67$ lbs. Total canopy volume developed by the shrub vegetation in the area was $22,462,878.50$ $\mathrm{m}^{3} / \mathrm{ha}$. The canopy volume has a correlation with carbon storage in shrubs, so shrubs are potential as the initial alternative vegetation or pioneer plants for reforestation of degraded land.
\end{abstract}

Keywords: shrubs, carbon storage, canopy volume

\section{INTRODUCTION}

The increase in percentage of critical lands in South Kalimantan, mostly wetlands, requires quick and sustainable recovery. Woody plants either trees or shrubs are plants that are often chosen as major plants in reforestation and land revitalization. Selection is often done because woody plants grow for a relatively long period of time and have a high percentage of survival after minimal planting.

Shrubs are small or short-stemmed woody plants with many branches, and not categorized seasonal plants (Sutaryo, 2009). These plants have a height of less than 5 meters and most of them have a lot of branches near the main stem (Eddie, 2007). According to Wahyudi (2009), based on its size, shrubs are divided into three types, high shrubs (maximum height of 4.5 meters), medium shrubs ( 1 meter), and low shrub (from 0.3 to 1 meter).

An analysis of the potential of shrubs in vegetation indicated that shrubs had an important role in greening a city either in the mixed vegetation or vegetation filled with shrub strata (Rahmani, 2016). In addition, shrub is a type of vegetation that has high weather resistance, but shows a rapid growth compared to trees (Werdiningsih, 2007).

Those basic characteristics become the bases of the study on the estimation of carbon storage in shrubs and the potential of shrubs as the alternative in the recovery of degraded land.

Cempaka Subdistrict, with hilly areas and wetlands, is one of the areas with high distribution of shrubs. The area of shrubs in Cempaka Subdistrict based on data from Banjarbaru municipality is about 5,675.116 hectares or $56,751,173.940 \mathrm{~m}^{2}$. There are four villages in Cempaka Subdistrict, namely Palam, Bangkal, Sungai Tiung, and Cempaka (BAPPEDA Banjarbaru city, 2008). Cover area of shrubs in each village can be seen in Table 1. 
Table 1. Area of Shrubs in Cempaka Subdistrict (BAPPEDA Banjarbaru, 2008)

\begin{tabular}{|c|c|c|}
\hline \multicolumn{3}{|c|}{ Area of shrubs in Banjarbaru } \\
\hline VILLAGE & $\mathrm{Ha}$ & $\mathrm{m}^{2}$ \\
\hline Palam & 824,488 & $8,244,887.29$ \\
\hline Bangkal & $1,263.676$ & $12,636,763.71$ \\
\hline Sungai Tiung & $1,157.640$ & $11,576,404.77$ \\
\hline Cempaka & $2,429.312$ & $24,293,118.17$ \\
\hline Total & $5,675.116$ & $56,751,173.94$ \\
\hline
\end{tabular}

\section{MATERIALS AND METHODS}

The study was conducted in Cempaka Subdistrict, Banjarbaru. Cempaka Subdistrict was selected because the distribution of woody shrubs in this area is quite high (Banjarbaru municipality, 2007). In addition, the level of critical lands in Cempaka Subdistrict is quite high, and the lands are overgrown by shrubs. Samples were taken at three stations. Each station consisted of three plots of $4 \times 4 \mathrm{~m}$. Each woody shrubs found in sample plots was then measured.

Carbon storage in shrubs was estimated using a non-destructive method by the stem diameter. The stem diameters were converted into a table of the average carbon estimation to obtain the estimated amount of carbon storage. The table of carbon estimation conversion (Table 2) was used based on Nowak et al., (2006) as follows:

Table 2. Average estimation of carbon storage in shrubs (Nowak et al., 2006)

\begin{tabular}{|c|c|c|c|c|c|c|c|c|}
\hline \multirow{2}{*}{$\begin{array}{l}\text { Diameter of } \\
\text { stem (inch) }\end{array}$} & \multicolumn{3}{|c|}{ Carbon storage } & \multicolumn{3}{|c|}{ Carbon storage } & \multicolumn{2}{|c|}{$\begin{array}{l}\text { Pollution } \\
\text { cleaning }\end{array}$} \\
\hline & (lbs) & $(\$)$ & $(\mathrm{mil})^{*}$ & (Lbs/yr) & $(\$ / y r)$ & $(\mathrm{mil})^{*}$ & (lbs) & $(\$)$ \\
\hline $1-3$ & 6 & 0.06 & 20 & 1.8 & 0.02 & 7 & 0.1 & 0.21 \\
\hline $3-6$ & 41 & 0.38 & 150 & 7.1 & 0.07 & 26 & 0.3 & 0.67 \\
\hline $6-9$ & 143 & 1.31 & 520 & 14.1 & 0.13 & 51 & 0.6 & 1.48 \\
\hline $9-12$ & 310 & 2.85 & 1,130 & 19.5 & 0.18 & 71 & 0.9 & 2.12 \\
\hline $12-15$ & 506 & 4.66 & 1,850 & 21.6 & 0.20 & 79 & 07 & 1.72 \\
\hline $15-18$ & 854 & 7.87 & 3,130 & 35.2 & 0.32 & 129 & 0.9 & 2.12 \\
\hline $18-21$ & 1,185 & 10.92 & 4,340 & 36.9 & 0.34 & 135 & 1.7 & 4.13 \\
\hline $21-24$ & 1,815 & 16.72 & 6,650 & 44.8 & 0.41 & 164 & 1.7 & 4.21 \\
\hline $24-27$ & 2,408 & 22.18 & 8,820 & 58.4 & 0.54 & 214 & 1.6 & 4.03 \\
\hline $27-30$ & 2.780 & 25.61 & 10,180 & 76.6 & 0.71 & 281 & 1.2 & 2.99 \\
\hline $30+$ & 5,347 & 49.25 & 19,580 & 106.5 & 0.98 & 290 & 2.8 & 7.06 \\
\hline
\end{tabular}

*mil: the number of vehicles producing emmission equivalent with plants

The shrub volume was measured for its plant unity in the sample plot of $4 \mathrm{~m} \times 4 \mathrm{~m}$ using the method of Arlt et al. (2008) by measuring the volume of the shrub canopy. Shrub canopy was estimated by measuring the height of stem from the ground level to the top of canopy. The canopy height was then measured from the bottom to the top of the canopy. Next, the types of canopy to be estimated were specified using formulas and types of canopy volume (Figure 1). The units of canopy volume in every shrub found in sample plots were summed up to obtain the total canopy volume. 


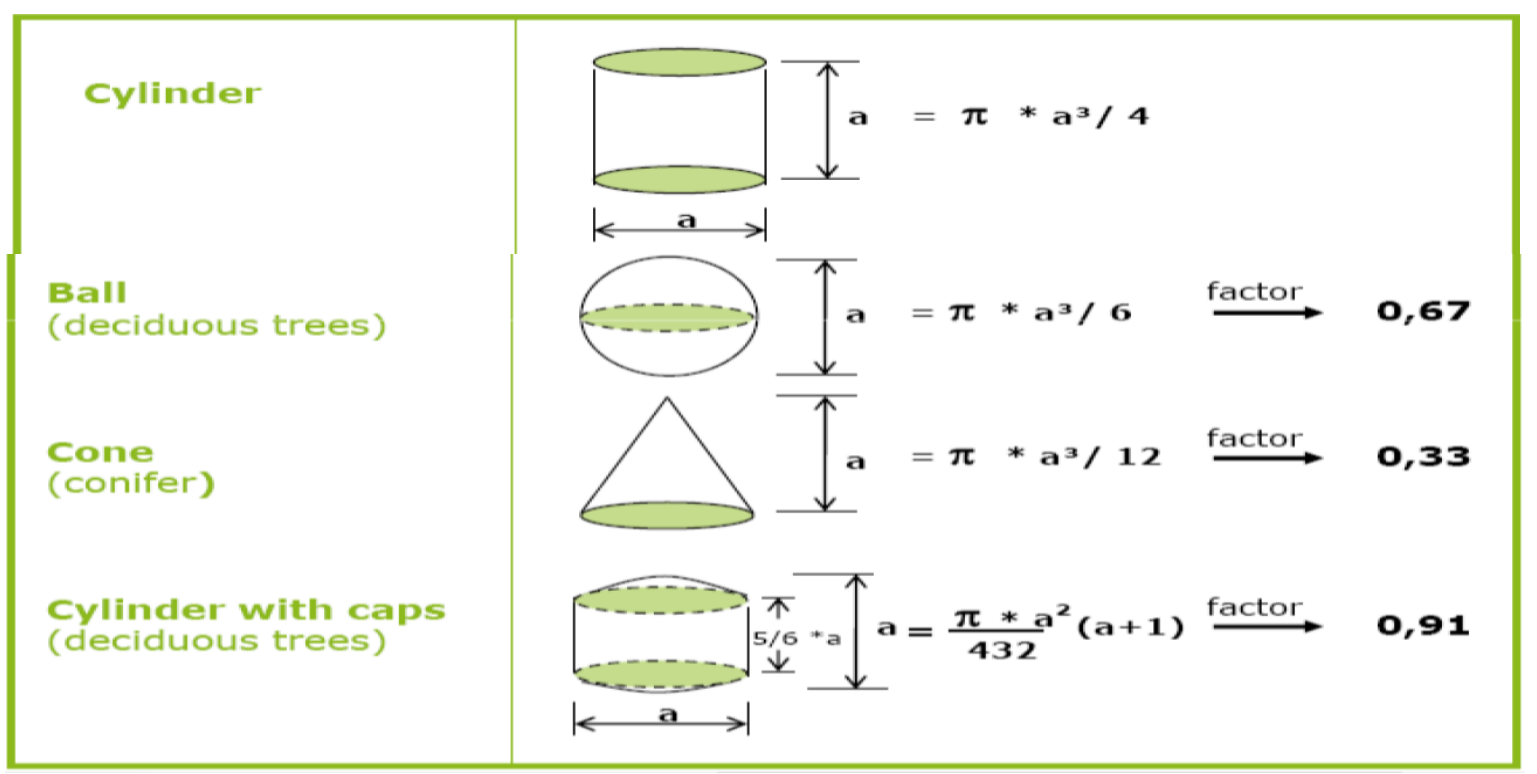

Figure 1 Canopy dimension patterns and canopy volume determination (Arlt et al., 2008)

The volume of a single field containing the shrub vegetation was calculated using the volume measurement of canopy dimension (Arlt et al., 2008). The results were then correlated with the total amount of carbon storage per a single field using the Pearson correlation analysis. This analysis was conducted to find out the relationship between the canopy volume and the amount of carbon storage in a plot of shrub vegetation.

\section{RESULTS AND DISCUSSION}

Carbon storage describes that the size of plant body is associated with its response to the plant's need of light (Hartmann and Messier, 2011). The value of carbon storage states the number of carbon that can be absorbed by plants in the form of biomass. The increasing amount of carbon should be balanced with the amount absorbed by plants. Thus, the number of plants that should be planted in an area can be predicted to balance the amount of free carbon in the air. The value of carbon storage estimation in the residential area with yards was from 0.77 to $4.15 \mathrm{~kg} / \mathrm{m}^{2}$ (Al-Fitr, 2014).

The estimation results of carbon storage in shrubs in Cempaka Subdistrict can be seen in Table 3. Based on the results, it can be found out that the average value of carbon storage in shrubs per plot was 15.54 $\mathrm{lbs} / \mathrm{m}^{2} /$ day. Meanwhile, the average canopy volume per plot of land was $0.40 \mathrm{~m}^{3}$. Thus, it can be estimated that in 1 ha of plants the shrubs can absorb the carbon at 155,416.67 lbs.

Table 3 Estimation of storage carbon and canopy volume in shrubs in Cempaka Subdistrict

\begin{tabular}{cccc}
\hline Station & Plot & Total carbon storage $(\mathrm{lbs})$ & Total canopy volume $\left(\mathrm{m}^{3}\right)$ \\
\hline 1 & 1 & 84.00 & 0.15 \\
& 2 & 300.00 & 5.12 \\
2 & 3 & 198.00 & 1.99 \\
& 1 & 180.00 & 5.16 \\
\multirow{2}{*}{3} & 2 & 168.00 & 0.72 \\
& 3 & 150.00 & 5.12 \\
& 1 & 366.00 & 22.33 \\
& 2 & 516.00 & 12.40 \\
& 3 & 276.00 & 4.00 \\
\hline \multicolumn{2}{c}{} & 248.67 & 6.33 \\
\hline
\end{tabular}

The estimation of carbon storage was obtained based on the estimated amount of shrub canopy volume. The estimation value of the shrub volume in Cempaka subdistrict with 
an area of $5,675.12$ ha was $22,462,878.50$ $\mathrm{m}^{3} / \mathrm{ha}$.

The population of shrubs in Cempaka subdistrict based on data from aerial photographs in 2007 (Figure 2) and data from BAPPEDA Banjarbaru (2008) cover more acreage. The area of shrub vegetation is not only limited to how much area covered by the shrubs but also related to the thickness of the cover shaded by the vegetation. The thickness will certainly affect the surrounding environmental conditions such as temperature and humidity (Fandeli, 2004).

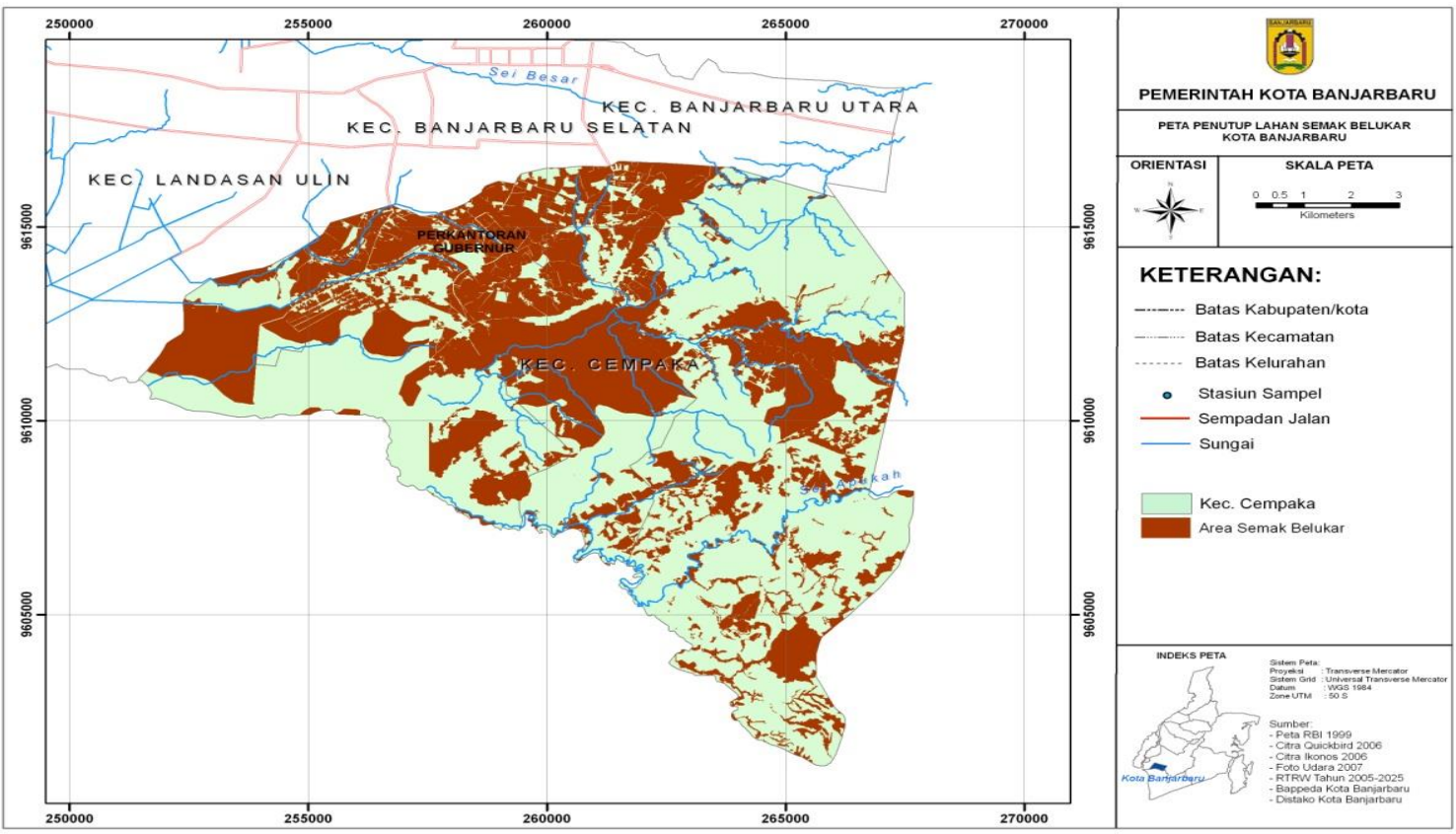

Figure 1 Map of Shrubland in Cempaka Subdistrict (Banjarbaru Municipality ${ }^{2}, 2007$ )

Total canopy volume per sample plot in each sampling plot was correlated with the total carbon storage. The results of the Pearson correlation analysis showed a correlation value of 0.713 . This value indicated that the canopy volume had a correlation with carbon storage in shrubs. This may indicate that the wider the canopy volume, the higher the capacity of shrubs to store carbon.

The width of canopy cover shaped by foliage gave effects to the micro climate change such as a decrease in temperature and increase in humidity (Rahmani, 2011). This can occur because the transpiration from the leaves can give the effect of decreased temperature and increased humidity (Edmunds \& John, 2011). A decrease in temperature and increase in humidity occur because of the processes of transpiration and photosynthesis for the exchange of $\mathrm{O}_{2}$ and $\mathrm{CO}_{2}$. These processes, of course, occur in the leaves that form the canopy.

The efforts to reduce greenhouse gases in the atmosphere, especially $\mathrm{CO}_{2}$, are carried out not only by reducing the emissions, but also by increasing the absorption of greenhouse gases. The existence of plants as the carbon sink in the atmosphere results in the decrease in $\mathrm{CO}_{2}$ (Bouwman, 1990).

Shrubs are small or short-stemmed woody plants that generally have many branches and not categorized seasonal plants (Sutaryo, 2009). These plants have a height of less than 5 meters and most have a lot branches near the main stem (Eddie, 2007). According to Wahyudi (2009), based on their size, shrubs are divided into three types, namely high shrubs (maximum height of 4.5 meters), medium shrubs (1 meter) and low shrub (from 0.3 to 1 meter).

According to a team of lowa Association of Naturalist (1994), shrubs have many branches with several major branches stemmed from a single point and have a height of less than 15 feet (4 meters). This characteristic sets it apart from a small tree that has only one main trunk, (Figure 3). Additionally, shrub is a type of vegetation that has high weather resistance and rapid growth (Werdiningsih, 2007). 

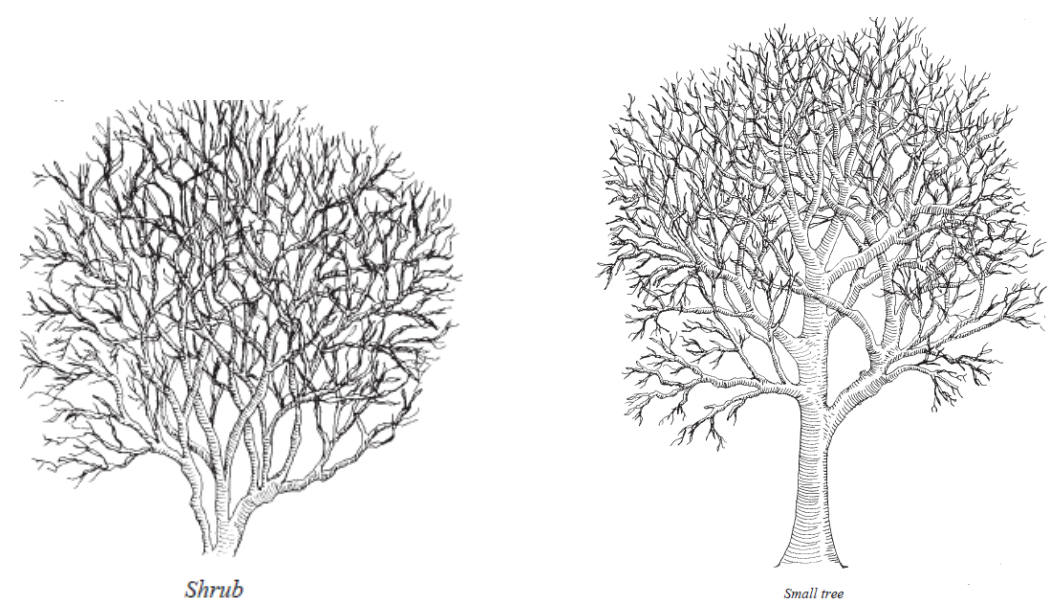

Figure 2 Comparison of branching characteristics between shrub and tree

According to Arlt et al., (2008) the potential of shrub canopy as one of the components of green open space can be measured by determining the volume of each shrub canopy. The canopy volume can be used as the main indicator for determining the potential of a plant while the indicators for ecological potential can be in the forms of the prevention of soil erosion, reflection and absorption of energy radiation, dust and noise filteration, keeping air quality, and absorbing water and minerals from soil (Figure 4).

Even today, urban areas are usually planted with a wide variety of plant species either long-lived plants, short-lived plants, creepers, climbers, shrubs, or low and high trees, and there also are cattle in the areas (Irwan 2008).

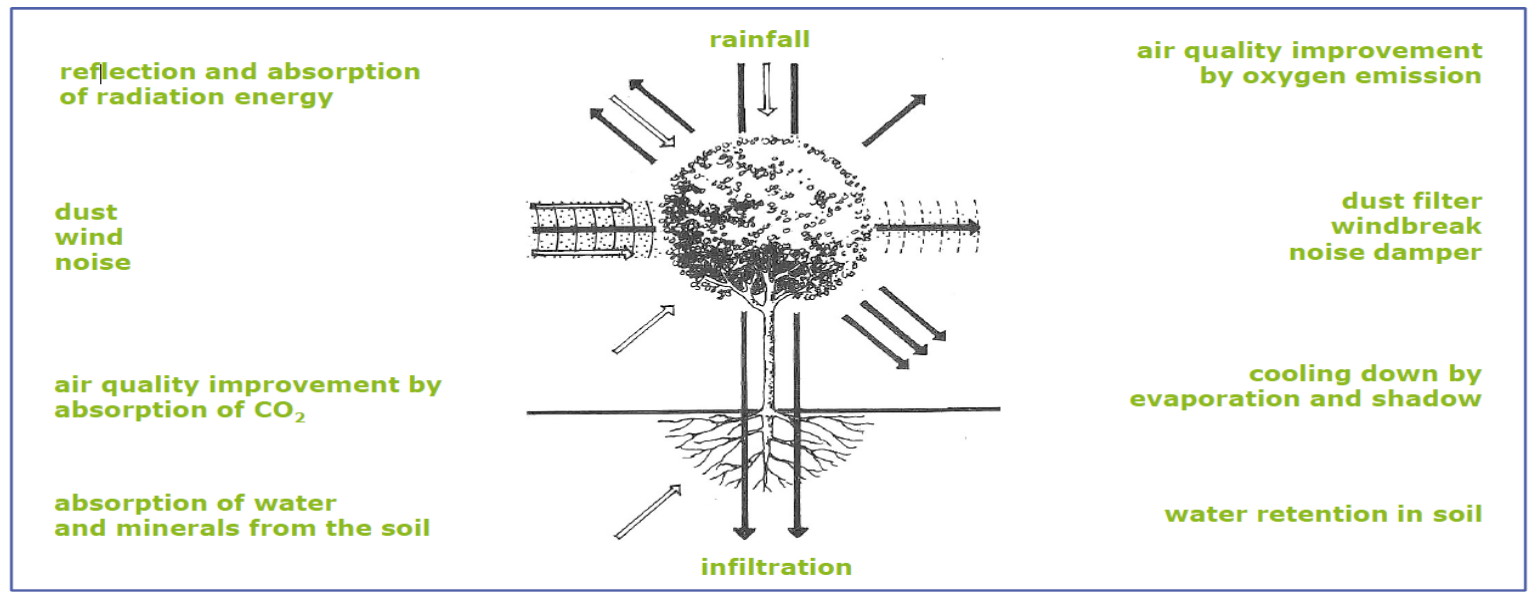

Figure 3 Scheme of vegetation functions (Arlt et al., 2008)

Shrub is one of the major plants with high dominance level in the area of Cempaka. The high number of critical lands in Cempaka, where shrubs largely overgrow, shows that this vegetation stratum can maintain and improve the quality of soil and environmental conditions. It can be seen from the various special characteristics of shrub vegetation. The shortcomings possessed by trees are that they take a long time to grow and have lower percentage of growth. Meanwhile, shrub vegetation has a role as the natural cover when there is no tree growing around the area or becomes the vegetation component of the land as one of the vegetation levels (Rahmani, 2016).

Good vegetation patterns contain each element of vegetation components, namely trees and understory plants (shrubs, bushes, and grass). Shrub is an element that its existence is necessary and important in green open spaces (Nugrahini, 2006). Thus, determining shrubs as the initial alternative vegetation or pioneer plants for reforestation 
of degraded land is an ideal choice in accordance with the structure that has been provided by nature.

\section{CONCLUSIONS}

Carbon storage in shrubs in the area of Cempaka, Banjarbaru, was 155,416.67 $\mathrm{lbs} / \mathrm{ha}$, and the total canopy volume formed by the shrub vegetation in the area was $22,462,878.50 \mathrm{~m}^{3} / \mathrm{ha}$.

The canopy volume is correlated with the carbon storage in the shrubs so the shrub vegetation is potential as the initial alternative vegetation or pioneer plants for reforestation of degraded lands.

\section{REFERENCES}

Al Fitri, S.H. (2014). Estimation of Carbon Reserve in Woody Vegetation in Green Open Spaces of Residential Areas in South Banjarbaru. Thesis. Lambung Mangkurat University, Banjarbaru, South Kalimantan, Indonesia

Arlt, G., Lehmann, I. and Deilmann, C. (2008). Urban Green Volume - A Quality Indicator. Leibniz Institute of Ecological and Regional Development. German.

Banjarbaru Municipality (2007). Index Classes of Vegetation in Banjarbaru.

BAPPEDA Banjarbaru. 2008. Inventory Data of Species and Location of Open Spaces in Banjarbaru City, 2008.

Bouwman, A.F. (1990). Soils and The Green House Effect. John Wiley and Sons. New York.

Eddie, C. (2007). Field Guide to Trees and Shrubs of Eastern Queensland Oil and Gas Fields. Santos Ltd, Adelaide. Australia.

Edmunds, S. and John, L. (2011). Environmental Administration. The University of California Riverside.

Fandeli, C. (2004). Urban Forestry. Gadjah Mada University, Yogjakarta.

Hartmann, H., and Messier, C. (2011). Interannual variation in competitive interactions from natural and anthropogenic disturbances in a temperate forest tree species: Implications for ecological interpretation. Forest Ecology and Management. Vol. 261. pp:19361944.
Irwan, Z.D. (2008). Exploration of Conceptual Utilization of Yards. Harian Kabar Indonesia.

Nowak, D.J., Robert, E.H.I., Daniel, E.C., Jack, C.S. and Jeffrey, T.W. (2006). Assessing Urban Forest Effect and Values. United State Department of Agriculture (USDA), The United States of America.

Rahmani, D.R. (2011). Potential of Shrub Vegetation in the Villages of Bangkal, Palam, and Sungai Tiung, Cempaka Subdistrict, Banjarbaru. Thesis. Unlam, Banjarbaru.

Rahmani, D.R. (2016). Variation in Vegetation Cover of Shrub as a Vegetation Candidate for Green Open Space Component in Cempaka Subdistrict, Banjarbaru. Tropical Wetland Journal $2: 42-48$.

Sutaryo, D. (2009). Biomass Calculation. An Introduction for the study of Carbon and Carbon Trade. Wetlands International Indonesia Programme, Bogor.

Tim lowa Association of Naturalists (1994). lowa's Shrubs and Vines. lowa Association of Naturalists Publication, lowa.

Wahyudi (2009). Supply of Urban Green Open Spaces in Ordo City I, Kudus Regency. Diponegoro University. Semarang.

Werdiningsih, H. (2007). A Study of Patterns in Green Open Spaces in Residential Area Semarang. Jurnal Ilmiah Perancangan Kota dan Pemukiman. 6: 87-96. 